\title{
Alveolar echinococcosis in patient after cadaveric kidney transplantation
}

\author{
S. DRAŽILOVÁ ${ }^{1}$, J. KINČEKOVÁ ${ }^{2}$ L'. BEŇA ${ }^{3}$, M. ZACHAR ${ }^{4}$, M. ŠVAJDLER ${ }^{5}$, P. ZAVACKÝ $^{6}$, P. JARČUŠKA $^{7}$
}

\author{
${ }^{1}$ Dept. of Internal Medicine, Hospital Poprad, Banícka 28, Poprad, Slovak Republic; \\ ${ }^{2}$ Institute of Parasitology of the Slovak Academy of the Science, Hlinkova 3, Košice, Slovak Republic; \\ ${ }^{3}$ Transplant Centre, 1st Dept. of Surgery, University Hospital, Tr. SNP 1, Košice, Slovak Republic; \\ ${ }^{4}$ Dept. of Radiology, University Hospital, Tr. SNP 1, Košice, Slovak Republic; ${ }^{5}$ Dept. of Pathology, University \\ Hospital, Tr. SNP 1, Košice, Slovak Republic; ${ }^{6}$ Dept. of Surgery, University Hospital, Tr. SNP 1, Košice, Slovak \\ Republic; ${ }^{7}$ 1st Dept. of Internal Medicine, University Hospital, Tr. SNP 1, Košice, Slovak Republic, \\ E-mail:petjarc@yahoo.com
}

\begin{abstract}
Summary
52-years old man years following the kidney transplantation from deceased donor was admitted to the hospital with fever and progressive abdominal pain. The patient was diagnosed with chronic hepatitis $\mathrm{C}$ seven years before admission. Graft function in posttransplant period was stable and optimal, the patient was treated with standard maintenance immunosupresive protocol (cyclosporine A, mycophenolate mofetil and low-dose prednison), metylprednisolon bolus therapy $\left(1 \mathrm{~g} / \mathrm{m}^{2}\right.$ body surface area), was administered two months prior to admission due to creeping creatinine (suspection of acute rejection was not confirmed by biopsy). Empiric antibiotic treatment due to febrile status was ineffective. Abdominal ultrasound and computer tomography (CT) scan revealed three tumorous lesions in the liver, radical surgical intervention was not executable. Histological examination of the tissue from the lesions demostrated alveolar echinococcosis, serology for Echinoccocus multilocularis was positive. Long-term treatment by mebendazol $200 \mathrm{mg}$ twice daily led to disappearance of the clinical symptoms, but after the therapy cessasion patient was again hospitalized with fever and progression of cystic lesions in CT scan. Following the mebendazol therapy reinstalation the clinical course of echinococcosis was improved and remained stable, transplant kidney failure occurred due to progression of interstitial fibrosis/tubular atrophy and chronic haemodialysis was initiated one year later.
\end{abstract}

Keywords: Echinococcosis; kidney transplantation; antiparasitic treatment; immunosuppressive treatment; chronic hepatitis $\mathrm{C}$

\section{Introduction}

Hippokrates was likely the first who has described echinococcosis in $369 \mathrm{BC}$. Today, according to WHO opinion, echinococcal infections belong to five principal ,neglected zoonotic diseases". Based on understanding of life cycle we now distinguish four Echinococcus species: Echinococcus multilocularis, E. granulosus, E. vogeli and E. oligarthrus (Morar \& Feldman, 2003; Kern et al., 2011). Echinococcus species are zoonotic agents causing disease in animals and infecting humans after accidental ingestion of viable eggs from definitive hosts (foxes, rarely dogs and cats) or through the ingestion of contaminated products (Miterpáková et al., 2009; Kern et al., 2011; Geyer et al., 2011). Two diseases are clinically relevant - cystic echinococcosis caused by larval stage of E. granulosus and alveolar echinococcosis caused by E. multilocularis. Alveolar echinococcosis is sporadic infection restricted to northern hemisphere, cystic echinococcosis is endemic in many countries around the world. Central Europe is endemic area for E. multilocularis (Kern et al., 2011). Recent Swiss report documented an incidence of alveolar echinococcosis 0.26 cases per 100000 population annually (Schweiger, 2007). In Slovakia, the first E. multilocularis infection in animal was described in 1999 (Dubinský et al., 1999), first animal-to-human transmission was found in 2000 (Kinčeková et al., 2001). To date 16 patients with alveolar echinococcosis have been diagnosed in Slovakia, the most of them in regions Žilina and Prešov - in the regions, where $60-80 \%$ of fox population is infected with $E$. multilocularis (Miterpáková et al., 2006). The most common localization of echinococcal infection is the liver followed by lungs. Cystic echinococcosis (E. granulosus) may develop silently over years and decades until signs and symptoms are clinically relevant. Hydatid cyst grows aproximatelly $1 \mathrm{~cm}$ per year (Romig et al., 1986; Ahmadi $\&$ Hamidi, 2010). Alveolar echinococcosis is a life-threatening disease. It can metastasize to remote organs, the most dangerous localization of filial focuses is the brain. Mortality of untreated alveolar echinococcosis exceeds $90 \%, 5$-years mortality of treated alveolar echinococcosis is $88 \%$ (Kern et al., 2011; Bresson-Hadni et al., 2000). 
A surgical extirpation of cysts is not always successful owing to their ability to form metastatic foci in secondarily infected organs (Kinčeková et al., 2008). The chemotherapy of alveolar echinococcosis with available anthelmintics (benzimidazoles, praziquantel a.o.) has only the parasitostatic effect and is therefore performed over many years, often through the whole patient's life. This brings the risk of adverse reactions to the drugs. The therapy for alveolar echinococcosis may be complicated with generalized immunosuppression caused by the parasite itself. $E$. multilocularis is able to evade host immune response or modify it to ensure its long-lasting survival in the organism of the intermediate host (Vuitton et al., 2006). Application of immunomodulative substances could limit the growth of the parasite. Results of alternative therapeutical strategies with use of immunomodulators (Dvorožňáková et al., 2004, 2008, 2009; Porubcová et al., 2007a) contributed to higher efficacy of the anti-echinococcus treatment.

Here we present the case report of 52-years old patient with chronic viral hepatitis type $\mathrm{C}(\mathrm{HCV})$ in whom alveolar echinococcosis emerged nine years following the kidney transplantation.

\section{Case report}

Patient (born in 1956) with the basal diagnosis of chronic glomerulonephritis in ending stage of renal disease dialysed from 1988 was transplanted in 1999 with kidney from deceased donor. Recipient's human leucocyte antigen HLA was A1, A11, B21, B44, DR11, DR14, the rest of transplant variables was standard. In $2001 \mathrm{HCV}$ positivity was noted in recipient and blind liver biopsy was performed with the histological findings of chronic viral hepatitis $\mathrm{C}$ grade 1, stage 2. Maintenance immunosuppression consisted of cyclosporine A, mycophenolate mofetil and low-dose prednison. In 2004 kidney graft biopsy was performed due to creeping creatinine with histological confirmation of interstitial fibrosis/tubular atrophy, angiotensin-converting enzymeinhibitors were introduced with partial improvment of the graft function measured by eGFR. In January 2008 bolus therapy of metylprednisolon

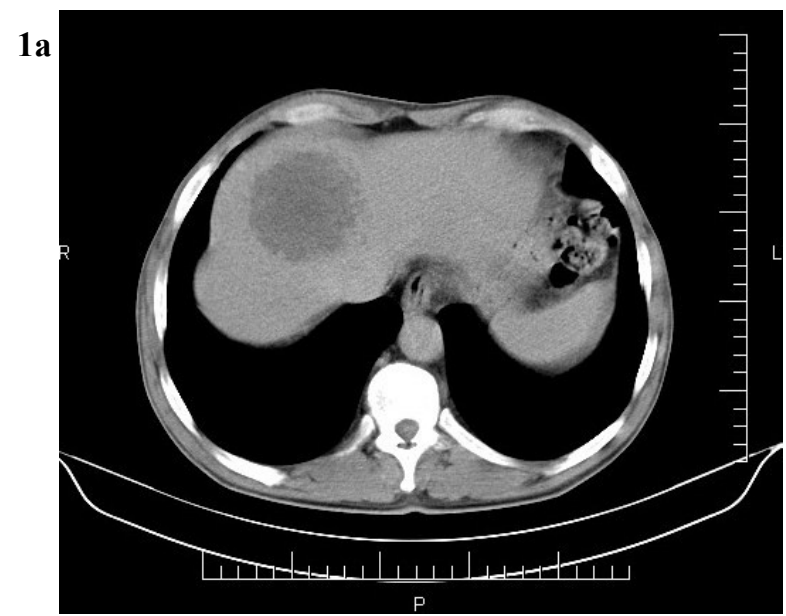

( $1.5 \mathrm{~g} / \mathrm{m}^{2}$ body surface area) with tappered prednison was installed due to suspection of acute rejection. This suspection was not confirmed by biopsy, steroids were discontinued. During this hospitalization due to abnormal resorption of cyclosporine A switch to tacrolimus was performed. Discharge creatinine concentration in patient was $217 \mathrm{mkat} / \mathrm{l}$. In March 2008, the patient was admitted to Hospital Poprad because of the febrile status of unknown origin. He was suffered of intensive dull pain in right hypochondrium and losed 4 kilograms of weight in two weeks. Objectively, hepatomegaly ( $+3 \mathrm{~cm}$ in medioclavicular line) of consistence III Naegeli was noted, no icterus, ascites, oedema or dermatological stigmata of liver cirrhosis were present. In laboratory screening some inflammatory parameters were elevated (FW: 128/140; CRP: 128 ng/ml; leucocytes: $10.5 \times 10^{9} / 1$; neutrophiles $72 \%$; procalcitonine semiquantitatively $<0.5 \mathrm{ng} / \mathrm{ml}$ ), mild hypoproteinemia and hypoalbuminemia (total proteins: $56.6 \mathrm{~g} / \mathrm{l}$; albumine: $30.6 \mathrm{~g} / \mathrm{l}$ ) were noted as well as BUN retention with moderate progression in comparison with previous controls $(15.58 \mathrm{mmol} / \mathrm{l}$; creatinemia: $267.8 \mathrm{mmol} / \mathrm{l})$ and mild elevation of cholestatic enzymes (GMT: $3.48 \mathrm{mkat} / \mathrm{l}$; ALP: $2.52 \mathrm{mkat} / \mathrm{l}$ ). Total bilirubine, conjugated bilirubine, AST and ALT levels were normal. Heavy normocyte anemia was noted (haemoglobine: $72 \mathrm{~g} / 1$; haematocrite: 0.22 ; erythrocytes: $2.54 \times 10^{12} / 1$ ). Microbiological evaluation (throat swab, nose swab, urine and blood culture) were repeatedly negative. In abdominal ultrasonography multiple large lobed focuses in both liver lobes were revealed. CT scan of the liver proved smooth surface and proper density, in segments S8, S4 and S6 hypodense focuses $64 \mathrm{~mm}, 62 \mathrm{~mm}$ and $71 \mathrm{~mm}$ in diameter were present (Fig. 1). The level of alphafetoprotein was normal. We have started the empirical antimicrobial therapeutic combination of cefotaxime, ciprofloxacine and metronidazole together with decrease of immunosuppression, but it was inefective and episodes of fever continued. Patient was transfered to the Transplant Centre of University Hospital Košice and consecutively to the Department of Surgery of the same hospital. Diferentially, disseminated liver cancer and multilocular liver abscess of unknown aetiology were considered, taking into account

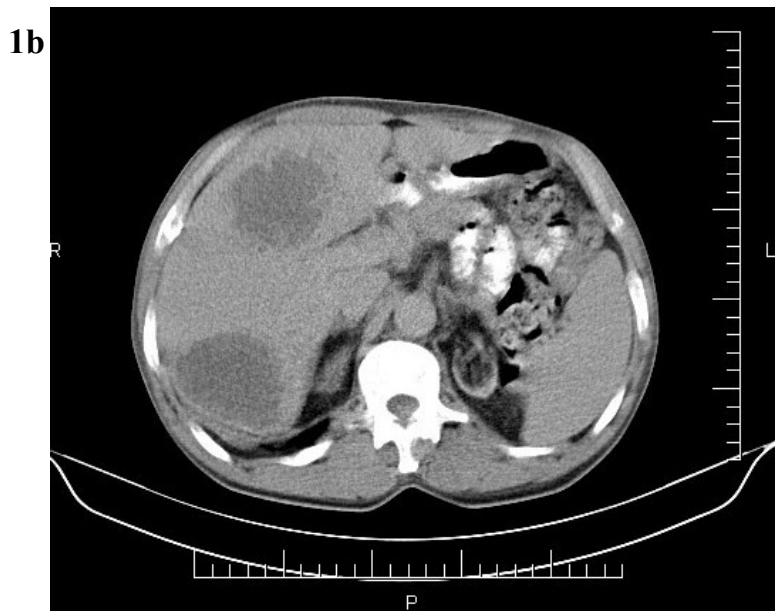

Fig. 1. Hepatic manifestation of the alveolar echinococcosis on CT scans at the time of diagnosis. Focuses of lower density in S8 with diameter of 230 $64 \mathrm{~mm}$ (1a), in S4 with diameter of $62 \mathrm{~mm}$ and S6 with diameter of $71 \mathrm{~mm}(1 \mathrm{~b})$. The liver is of smooth surface and proper density. 

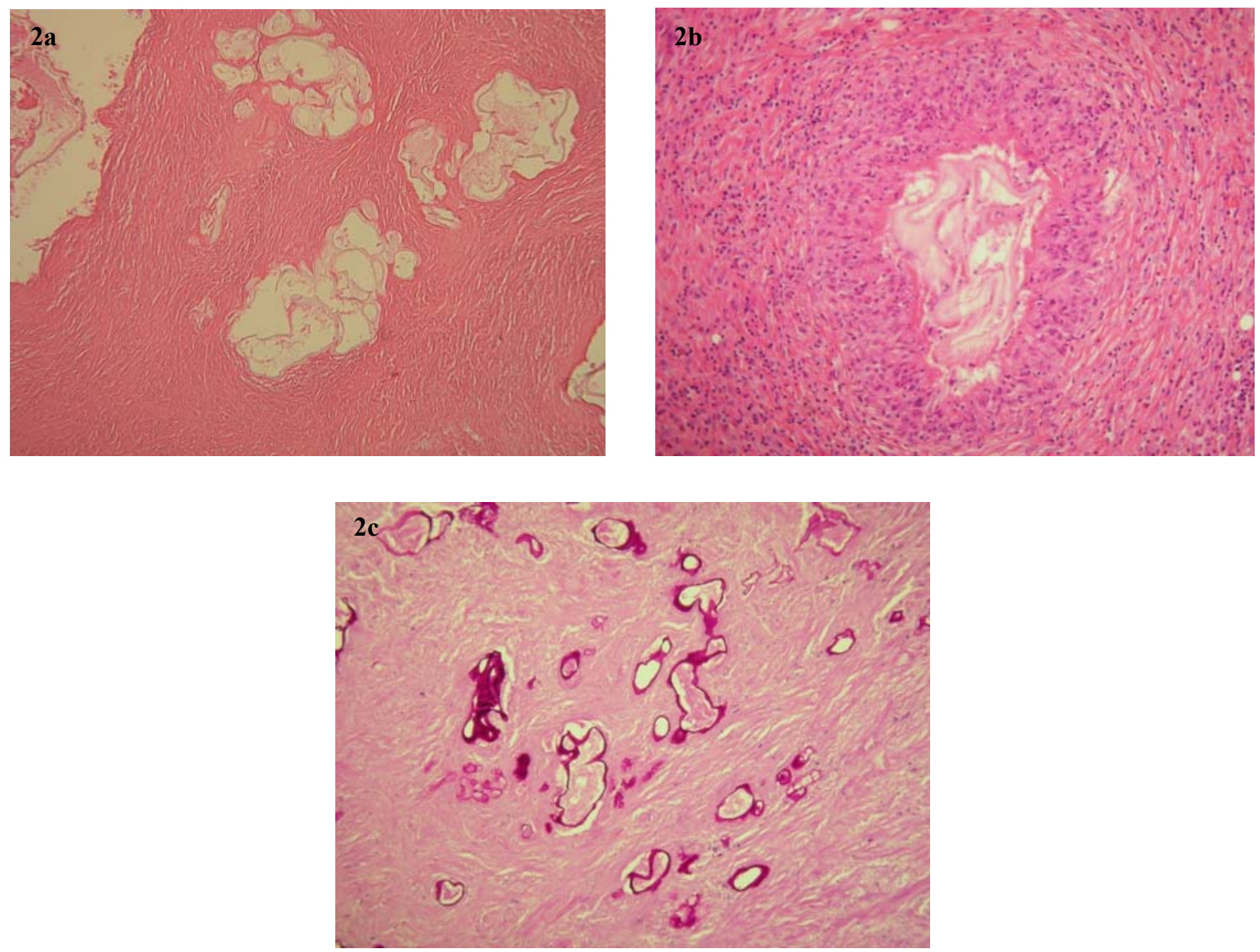

Fig. 2. Alveolar echinococcosis - histological findings. Alveoli of different sizes embedded in fibrous tissue. Haematoxylin and eosin (2a), Granulomatous reaction and inflammatory infiltrate containing many eosinophils and neutrophils. Haematoxylin and eosin (2b), Membranes stained with period acid-Schiff with diastase (2c).

inconclusive imaging results and clinical and laboratory course of the disease. Parasite aetiology of multilocular liver lesions was considered as well. Laparotomy with liver revision and multiple biopsies from patological lesions were performed with histomorphological confirmation of alveolar echinococcosis. Microscopically, many alveoli of different sizes and shapes were found. They were embedded in fibrous tissue with focal inflammatory infiltrate containing lymphocytes, eosinophils and neutrophils. Granulomatous reaction was focally seen. Alveolus wall was composed of glassy acellular membrane not staining with hematoxylin-eosin and positive with PAS-D. No protoscoleces were found (Fig. 2). This diagnosis was confirmed also histologically, echinococcal spreading was not confirmed.

Detection of specific Echinococcus spp. antibodies IgG in practice uses total native antigens or antigen fractions. As antigens there were used hydatic liquid (HL), antigen B isolated from HL and scolex antigen (SA) made out by homogenization of E. granulosus protoscoleces in phosphate buffered saline ( $\mathrm{pH}$ 7.2) followed by extraction. Pacient serum was also examined for specific $\operatorname{IgG}$ antibodies to $E$. multilocularis antigen Em2+ by indirect ELISA (Bordier
Affinity Products, Crissier, Switzerland). Results: antibodies to E. granulosus - medium titer 1:400-800 and $E$. multilocularis - negative. Following the diagnosis determination therapy with mebendazole $100 \mathrm{mg}$ bis in die (b.i.d.) was started and tacrolimus (immunosuppression) dose was minimized to $2 \mathrm{mg}$ per day. In april 2008 when patient was discharged from the hospital creatinaemia was $155 \mathrm{mmol} / 1$. In september 2008 patient was rehospitalized in Transplant Centre of University Hospital Košice because of febrilities following the unwarranted mebendazole discontinuation. With CT scan we have documented the progression of echinococcal infection, in the area of dominant lesions dissemination of small $(2-12 \mathrm{~mm}$ in diameter) locuses was found as well as three enlarged lymphatic nodes in anterior costophrenic angle and little right pleural effusion (Fig. 3). Following the mebendazol $200 \mathrm{mg}$ b.i.d. reinstallation febrilities dissapeared, this therapy was not discontinued since that time. Creatinaemia at the time of patient discharge was $183 \mathrm{mmol} / \mathrm{l}$.

No febrilities were registered in follow-up period, however, transplant kidney failure occured. In february 2009 regular dialysis was started $(28.3 \mathrm{mmol} / \mathrm{l}$; creatinaemia $465 \mu \mathrm{mol} / \mathrm{l}$; glomerular filtration: $0.14 \mathrm{ml} / \mathrm{s})$. Repeated CT 

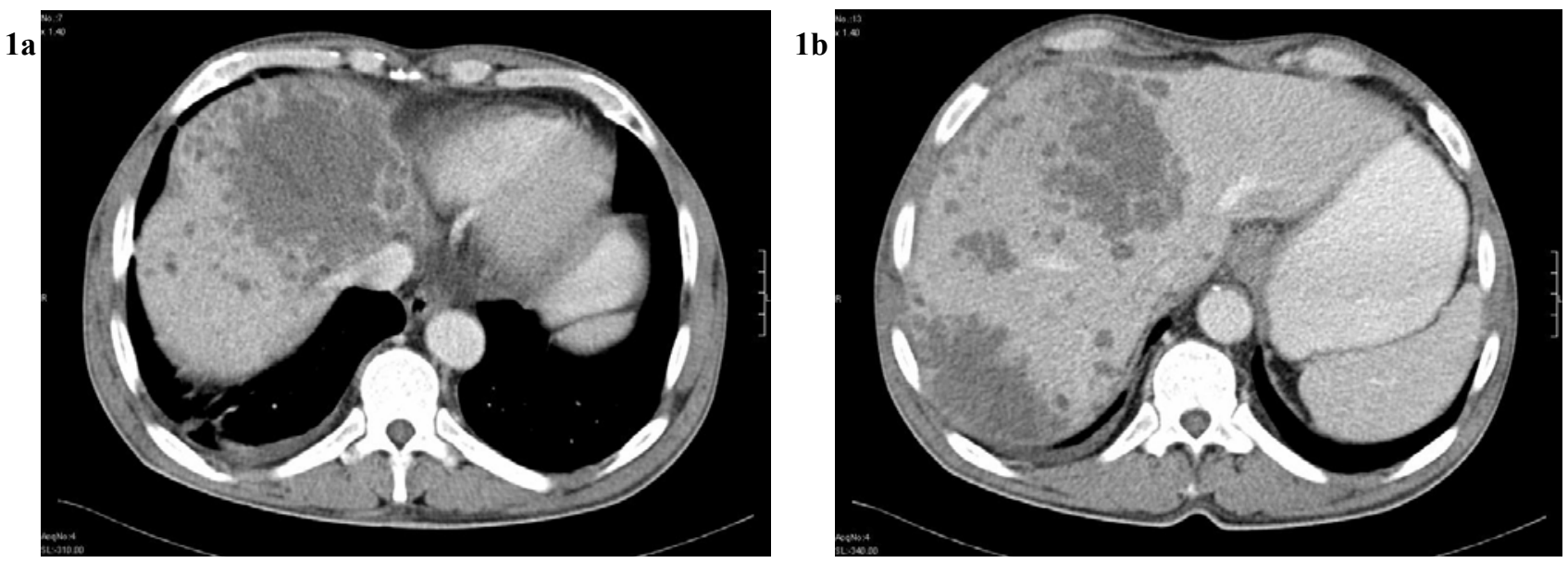

Fig. 3. Alveolar echinococcosis - findings in control CT scan. Progression of echinococcal lesions in S8 - diameter of $90 \mathrm{~mm}(3 \mathrm{a})$, in S4 - diameter of $86 \mathrm{~mm}$ and in S6 - diameter of $72 \mathrm{~mm}$. Secondary echinococcosis lesions are present.

scan did not prove echinococcosis progression. Because of chronic viral hepatitis type $\mathrm{C}$ monotherapy with pegylated interferone alfa-2a was indicated.

\section{Discussion}

Our patient comes from Poprad region where clinical manifestation of the echinococcosis is repeatedly described. Apart from the contact with domestic animals he did not carry any risk factor for echinococcosis infection transfer. The manifestation of alveolar echinococcosis was registered during the maintenance immunosuppressive therapy in patient with transplanted kidney and chronic hepatitis type C. Following the immunosuppression reduction and mebendazol discontinuation relapse of febrilities and echinococcosis infection progression occured. When mebendazole was reinstalled, no new manifestation of echinococcosis was registered and repeated CT scans have been stable. In our opinion, transplant kidney failure was the progression of interstitial fibrosis/tubular atrophy of the graft and it could be related to echinococcal infection. Cellular immune response, leading to granulomatous infiltration of periparasitic tissue, plays the dominant role in fight with echinococcus. Granuloma generation and fibrosis can restrict cyst growth, but also reduces anthelminthic drug transport to the lesion and thus may be the reason of partial or total ineffectiveness of treatment (Vuitton et al., 2006; Porubcová et al., 2007b).

It is accepted that immunosuppressive therapy can modify the course of echinococcal infection. Cyclosporine A has been found to have anti-parasitic effects against a variety of helminth and protozoan parasites and this activity could be mediated via cyclophilin. Colebrook et al. (2004) found cyclosporine A to be lethal for E. granulosus protoscoleces in vitro. Anti-E. granulosus effect of cyclosporine $\mathrm{A}$ in mouse model was confirmed by Hurd et al.(1993). However, anti-parasitic effect of cyclosporine A was not confirmed against E. multilocularis (Liance et al., 1992), the drug had no antiparasitic effect, although it lengthened the maturation time of protoscoleces. Tacrolimus can have the potential anti-E. granulosus effect as well (Cumino et al., 2010). These statements do not allow us to validate the effect of immunosuppressive therapy on the course of echinococcosis. However, it seems that immunosuppression, mainly with cyclosporine A, does not accelerate the course of echinococcal infection.

There are only scarce data regarding the influence of corticosteroid therapy on the echinococcosis course. Hildreth and Granholm (2003) showed that the treatment of mice with cortisone drastically increased both the number of $E$. multilocularis cysts and the average size of each cyst when the treatment occurred early in the infection course. Our patient has received low doses of prednisone during nine years following the kidney transplantation, two months prior to clinical manifestation of echinococcosis he did receive moreover three boluses of methylprednisolone.

The chemotherapy for alveolar echinococcosis with available anthelmintics (benzimidazoles) has only the parasitostatic effect. There is still no consensus regarding the effective dosage and duration of treatment, for either cystic or alveolar echinococcosis. Moreover, the results of treatment may be affected by immunological status of the host, host susceptibility and the actual stage of infection. Antiparasite therapy (albendazole, mebendazole) is complicated with generalized immunosupression caused by the parasite itself. E. multilocularis is able to evade host immune response or modify it to ensure its long-lasting survival in the patient organism (Vuitton et al., 2006). The host T-cell immunity significantly contributes to the control of alveolar echinococcosis in human patients as well as demonstrated by the rapid fatal outcome of the infection in an immunodeficient patient co-infected with human immunodeficiency virus (HIV) (Sailer et al. 1997). Upon restoration of CD4-immunocomptence in another AIDS-patient co-infected with E. multilocularis, the course of disease was positively influenced again (Zingg et al., 2004).

Sobrino et al. (1993) presented the case of a man with liver hydatidosis, who underwent heart transplantation. The immunosuppressive treatment had no effect on the size of E. multilocularis cysts, which were removed surgically, 
good results persisted after 3 years of follow-up. Kolligs et al. (2003) reported the case of a patient with subcutaneous alveolar echinococcosis 6 months after liver transplantation for HCV-related cirrhosis. Neither the explanted nor the transplantated liver revealed an echinococcus focus. The patient was curatively treated by surgical removal of the subcutaneous tumor and a postoperative therapy with albendazole. Furthermore, HCV reinfection (genotype 2b) was successfully treated with interferon alpha $2 b$ and ribavirine for 6 months. Gaultier et al. (2009) described $E$. granulosus infection in the liver of a patient with hepatitis $\mathrm{C}$ following the heart transplantation. Kim et al. (2011) published the case of a patient who underwent cytotoxic chemotherapy and allogeneic hematopoietic stem cell transplantation (HSCT) for acute myelogenous leukemia in the presence of hepatic cystic echinococcal infection. Successful management of the patient's disease processes required a multidisciplinary approach, which included systemic chemotherapy, HSCT, treatment of chronic graftversus-host-disease, and elective en bloc resection of the hepatic cyst.

Alveolar echinococcosis recidive following the liver transplantation is rather rare. (Bresson-Hadni et al. (2003) assessed 47 patients following the liver transplantation because of alveolar echinococcosis. Five-year survival was $71 \%$. Five-year survival without recurrence was $58 \%$. Major technical difficulties related either to previous laparotomies or to the loco-regional involvement were observed. The nine early deaths concerned patients with a long past-history of symptomatic alveolar echinococcosis (iterative cholangitis, secondary biliary cirrhosis). Five late deaths were directly related to ongoing alveolar echinococcosis, located in the brain in three cases, a very rare echinococcus location that was not investigated before liver transplantation in these patients.

There are sporadic case reports of echinococcal infection in patient with transplanted kidney. Cavdar et al. (2007) described cystic echinococcosis in right native kidney of the patient two years after the kidney transplantation. Asymptomatic hydatidosis was found accidentally in routine ultrasound control. Histological examination revealed the lamellary membrane of the hydatid cyst, serological tests for echinococcosis were negative. Palmiero et al. (2008) described the case report of the patient following the kidney transplantation, who was admitted to the hospital with the suspection for acute pancreatitis (icterus, abdominal pain, fever). In sonography, multiple fluid-filled cysts (up to $8 \mathrm{~mm}$ ) were found in the liver. The diagnosis of cystic hydatidosis was established. Cyclosporine A dose which was temporary diminished was increased again and the therapy with albendazole was performed. This enabled a prompt resolution of the disease and the progressive fibrous evolution of the cysts over the 18-month follow-up period, with no damage to renal function, which remained stable. Sqalli et al. (2009) reported the case of a renal allograft recipient who was diagnosed with hepatic cystic echinococcosis five months after kidney transplantation. The development of tapeworm larvae could have been encouraged by immunosuppressive therapy. Ultrasound and CT scan of abdomen revealed anechogenic perihepatic cystic mass. Hepatocellular enzymes were normal, serological tests for hydatidosis were negative. Needle biopsy revealed free protoscoleces and loose hooks suggesting hydatid cysts. Secondary loci of echinococcal infection were not found. The patient was successfully treated by surgical removal of the cyst and perioperative treatment with albendazole.

The first report of hepatic alveolar echinococcosis in a renal transplant recipient recorded Geyer et al. (2011). They described the case of an ABO-incompatible renal retransplant recipient maintained on an intensified immunosuppressive regimen for recurrent cellular rejection episodes and transplant glomerulopathy who presented with rapidly growing hepatic tumors, radiologically suggestive of hemangiosarcoma. Upon resection and pathological work-up, the lesions revealed alveolar echinococcosis. This diagnosis was confirmed by PCR. Albendazole oral therapy $200 \mathrm{mg}$ b.i.d. was started, immunosuppression therapy with tacrolimus, mycophenolate mofetil and prednisone reduced dose has been continued. Thirty-four months following the surgical revision neither the recidive of alveolar echinococcosis nor the kidney graft function worsening was registered. In the case presented, they observed an atypically rapid growth pattern of E. multilocularis that might have been due to the extent of the immunosuppressive regimen, which included repetitive anti-CD20 treatments. Retrospectively performed serological studies with enzyme-linked immunosorbent assays known to provide high sensitivity and specificity for the detection of echinococcosis in the general population, yielded ambiguous results in that immunocompromised host, which could be, in part, explained by B-cell depletion and its effects on antibody production and indirect actions on cellular immunity. This case documents an altered clinical course of the parasitosis and the challenge of serological diagnostic tools under an intensified regimen of immunosuppressive agents (Geyer et al., 2011).

Even though some immunosuppressive medicaments are thought to have the direct anti-parasitis effect, in patient following the organ transplantation progression of echinococcosis was registered with more rapid progression of alveolar echinococcosis patients. This could be described by T-cell imunity deficit in this group of patients (Kern et al., 2011). The subgroup of immunosuppressed patients did not form the antibodies against the echinococcus indicating the B-cell imunity deficit in these patients. Probably for that reason we did not find specific anti-E. multilocularis antibodies in our patient. Mean titer anti-E. granulosus antibodies is likely to be a result of low specificity of used antigens. Alveolar echinococcosis in our patient was uniquely determined by histology.

In all above mentioned case reports on cystic and alveolar echinococcosis including our case report the disease was initially manifested with progressive abdominal pain, in three cases febrilities of unknown origin were present without adequate reaction to antimicrobial treatment. In 
our patient the recidive of febrilities and progression of echinococcosis occured following the mebendazole treatment discontinuation. The probable cause of febrilities could be the cyst rupture into the biliary tree (Kern et al., 2011). It is therefore logical that antibiotic treatment in such a case could not be effective. It is important to stress the fact that in all patients the diagnosis of cystic or alveolar echinococcosis were not established prior to surgical intervention. Liver foci were interpreted as liver cancer or abscesses (Kinčeková et al., 2005). No patient was treated with anti-parasitic drugs prior to surgical intervention, patients were therefore threatened by the dissemination of the echinococcosis. In patients with anti-parasite treatment no recidive of the disease even after long time period was observed following the surgical removal of the cysts (Palmiero et al., 2008; Sqalli et al., 2009; Geyer et al., 2011). In our patient it was not possible to perform the extensive surgical removal of loci from the liver. Following the mebendazole discontinuation we have registered the progression of the disease, however, after the reinstallation of therapy no disease progression nor secondary lesions in different organs was registered. The influence of echinococcal infection and its treatment on the renal function in transplanted patients is also very interesting. During the disease manifestation worsening of renal parameters was registered which was probably caused by circulatory changes in kidney during febrilities. When the febrile status was managed, renal functions improved. In our patient creatinineamia was acceptable also during repeated hospitalizations, renal insufficiency progression and finally its failure with the need of chronic dialysis was in our opinion due to isterstitial fibrosis/tubular atrophy progression. There is a clinical evidence between HLA DR 11 and protection and HLA DR3 and DQ2 and severe clinical evolution of alveolar echinococcis (Eiermann et al., 1998). However, in our patient even in the presence of the protective HLA DR11 during the long-term immunosuppression therapy severe form of alveolar echinococcosis occured.

Our patient with alveolar echinococcosis has suffered also from chronic hepatitis $\mathrm{C}$. The golden standard of the chronic hepatitis $\mathrm{C}$ treatment is combined therapy with pegylated inteferon (IFN) and ribavirin (EASL Clinical Practice Guidelines, 2011). IFN-gamma is the component part of the Th1 answer (together with interleukin-2 induced by interleukin-12), in the dominance of the Th1 response over the Th2 response reduction of echinococcal loci in the liver was noticed (Vuitton \& Gottstein, 2010). The IFN treatment prevents the echinococcal lesions growth in animal as well as human model (Liance et al., 1998; Jenne et al., 1998). Anti-parasitic treatment leads to IFN-gamma level increase (Dvorožňáková et al., 2004). In our case report we did not administer the pegylated IFN treatment with ribavirin during the period with functioning kidney graft because it is widely known that the treatment of chronic hepatits $\mathrm{C}$ with IFN in patients with transplanted kidney can lead to the acute kidney graft rejection (Wéclawiack et al., 2008). The treatment with pegylated IFN alfa-2a was indicated following the kidney graft failure and after the beginning of regular dialysis in patient. Taking into account the fact that the patient has a severe hepatic lesion and is on regular dialysis, we are now considering the possibility to put the patient on the waiting list of combined liver - kidney transplantation. As far as we know there is no case of combined liver - kidney transplantation in liver echinococcosis described in the literature.

\section{Conclusion}

Echinococcosis can rarely occurres in the liver of patients following the kidney transplantation. It can be manifested by progressive abdominal pain and very often by febrile status. Imaging methods (ultrasound, CT and MRI scans) can reveal typical loci in the liver which are very often interpreted not correctly. The disease can often imitate liver cancer or liver abscess and it is inevitable to add the serological evaluation (and PCR) to prove echinococcosis. However, serological evaluation could be negative in some patients. In suspection for echinococcosis it is adviced to begin the anti-parasitic therapy prior to surgical intervention. Surgical removal of echinococcal foci is eligible. Following the surgical intervention immunosuppression therapy must be adjusted properly and anti-parasitic therapy must be administered for long time, often through the patient's life, to prevent the recidive or progression of the disease and formation of metastatic loci.

\section{Acknowledgement}

The study has been supported by the VEGA Project No. 2/0134/09 and by the Project "Application Centre for Protection of Humans, Animals and Plants against Parasites (ITMS-26220220018)" on the basis of support from Operational Programme Research and Development, funded by the European Regional Development Fund (P 0.8).

\section{References}

AHMADI, N. A., HAMIDI, M. (2010): Unusual localizations of human hydatid disease in Hamedan province, west of Iran. Helminthologia, 47(2): 94 - 98. DOI: 10.2478/s1168 7-010-0015-X

Bresson-Hadni, S., Vuitton, D. A., Bartholomot, B., Heyd, B., Godart, D., Meyer, J. P. (2000): A twenty-year history of alveolar echinococcosis: analysis of a series of 117 patients from eastern France. Eur. J. Gastroenterol. Hepatol., 12(3): 327 - 336. DOI: 10.1097/00042737-2000 12030-00011

Bresson-Hadni, S., Koch, S., Miguet, J. P., Gillet, M., Mantion, G. A., Heyd, B., Vuitton, D. A. (2003): Indications and results of liver transplantation for Echinococcus alveolar infection: an overview. Langenbecks. Arch. Surg., 388(4): 231 - 238. DOI: 10.1007/s00423-003-0394-2

Cavdar, C., Celik, A., Saglam, F., Toprak, O., Gungor, O., Tuna, B., Secil, M., Gulay, H., Camsari, T. (2007): Isolated hydatid disease of native kidney in a renal transplant recipient. Nephrol. Dial. Transplant., 22(2): $656-$ 
567. DOI: $10.1093 / \mathrm{ndt} / \mathrm{gf1} 644$

ColebrooK, A. L., Jenkins, D. J., Jones, M. K., TATARCZUCH, L., LightowlERS, M. W. (2004): Effect of cyclosporin A on the survival and ultrastructure of Echinococcus granulosus protoscoleces in vitro. Parasitology, 129(Pt 4): 497 - 504. DOI: 10.1017/S00311 82004005773

Cumino, A. C., LAMENZA, P., DenEGRI, G. M. (2010): Identification of functional FKB protein in Echinococcus granulosus: its involvement in the protoscolicidal action of rapamycin derivates and in calcium homeostasis. Int. J. Parasitol., 40(6): 651 - 661. DOI: 10.1016/j.ijpara.2009. 11.011

DUBINSKÝ, P., SVOBODOVÁ, V., TURČEKOVÁ, L., LITERÁK, I., MARTíneK, K., ReITEROVÁ, K., KolÁŘOVÁ, L., KLIMES̆, J., MRLÍK, V. (1999): Echinococcus multilocularis in Slovak Republic: The first record in red foxes (Vulpes vulpes). Helminthologia, 36(2): $105-110$

DVOROŽŇÁKOVÁ, E., HrČKOVÁ, G., BOROŠKOVÁ, Z., VELEBNÝ, S., DUBINSKÝ, P. (2004): Effect of treatment with free and liposomized albendazole on selected immunological parameters and cyst growth in mice infected with Echinococcus multilocularis. Parasitol. Int., 53: 315 - 325. DOI: 10.1016/j.parint.2004.05.001

DVOrožŇÁKovÁ, E., PORUBCOVÁ, J., ŠNÁBEL, V., FEDOROČKO, P. (2008): Immunomodulative effect of liposomized muramyltripeptide phosphatidylethanolamine (L-MTP-PE) on mice with alveolar echinococcosis and treated with albendazole. Parasitol. Res. 103: 919 - 929. DOI: $10.1007 / \mathrm{s} 00436-008-1077-2$

DvorožŇÁková, E., PorubcovÁ, J., ŠEvČíkovÁ, Z. (2009): Immune response of mice with alveolar echinococcosis to therapy with transfer factor, alone and in combination with albendazole. Parasitol. Res., 105: 1067 1076. DOI: $10.1007 / \mathrm{s} 00436-009-1520-\mathrm{z}$

EASL Clinical Practice Guidelines (2011): Management of hepatitis C virus infection. J. Hepatol., 55(2): 245 - 264

Eiermann, T. H., Bettens, F., Tiberghien, P., Schmitz, K., Beurton, I., Bresson-Hadni, S. (1998): HLA and alveolar echinococcosis. Tissue Antigens, 52(2): 124 - 129. DOI: $10.1111 /$ j.1399-0039.1998.tb02275.x

Gaultier, J. B., Hot, A., MAuservey, C., Dumortier, J., COPPÉRÉ, B., NINET, J. (2009): Granulomatous liver disease as the presenting feature of alveolar echinococcosis in an hepatitis C infected cardiac transplant patient. Rev. Med. Interne., 30(9): 812 - 825. DOI: 10.1016/j.revmed.20 08.11 .007

Geyer, M., Wilpert, J., Wiech, T., Theilacker, C., Stubanus, M., Kramer-Zucker, A., Fischer, K. G., Drognitz, O., Frydrychowicz, A., KERN, W., WAlZ, G., PISARSKI, P. (2011): Rapidly progressive hepatic alveolar echinococcosis in an ABO-incompatible renal transplant recipient. Transpl. Infect. Dis., 13(3): 278 - 284. DOI: 10.1111/j.1399-3062.2010.00583.x

GotTsteIN, B. (1992): Molecular and immunological diagnosis of echinococcosis. Clin. Microbiol. Rev., 5: 248 - 261

Hildreth, M. B., Granholm, N. H. (2003): Effect of mouse strain variations and cortisone treatment on the establishment and growth of primary Echinococcus multilocularis hydatid cysts. J. Parasitol., 89(3): 493 - 495. DOI: 10.1645/
0022-3395(2003)089[0493:EOMSVA]2.0.CO;2

Hurd, H., MACKenzIE, K. S., Chapell, L. H. (1993): Anthelmintic effects of cyclosporin A on protoscoleces and secondary hydatid cysts of Echinococcus granulosus in the mouse. Int. J. Parasitol., 23(3): 315 - 320. DOI: 10.1016/ 0020-7519(93)90005-J

Jenne, L., Kilwinski, J., RAdloff, P., Flick, W., Kern, P. (1998): Clinical efficacy of and immunologic alterations caused by interferon gamma therapy for alveolar echinococcosis. Clin. Infect. Dis., 26(2): 492 - 494. DOI: 10.1086/ 516316

KERN, P., GRÜNER, P., WAHLERS, K. (2011): Diagnosis and course of echinococcal disease in the transplant setting. Transpl. Infect. Dis., 13(3): 217 - 221. DOI: 10.1111/j.139 9-3062.2011.00643.x

Kim, J., Delioukina, M. L., Lee, W., Soriano, P., Prendergast, C., D'APuzzo, M., Dadwal, S. (2011): Successful allogeneic hematopoietic stem cell transplantation for acute myelogenous leukemia in a patient with hepatic echinococcal cyst managed by delayed hepatectomy. Transpl. Infect. Dis., 13(3): 273 - 277. DOI: 10.1111/j.1399-3062.2010.00578.x

Kinčeková J., Auer H., Reiterová K., Dubinský P., SzILÁgYiovÁ M., LAUKO L'., AsPÖCK H. (2001): The first case of autochtonous human alveolar echinococcosis in the Slovak Republic. Mitt. Österr. Ges. Tropenmed. Parasitol., 23: $33-38$

KinČEKOVÁ, J., DubinskÝ, P. JR., DVOroŽŇÁKOVÁ, E., Auer, H., HudaČKOVÁ, J., DAŇOVÁ, M., Stanislayová, M., StrakA, L., SzIlÁGYOvÁ, M. (2005): Diagnostika a výskyt alveolárnej echinokokózy na Slovensku. Čes. Slov. Gastroenterol. hepatol., 59 (1): $11-16$

Kinčeková, J., HrČKovÁ, G., Bober, J., Vrzgula, A., SZABADOŠOVÁ, V., BOHUŠ, P., ZACHAR, M. (2008): A rare case of alveolar echinococcosis in a 14-year-old child. Helminthologia, 45: 28 - 31. DOI: 10.2478/s11687-0080005-4

Kolligs, F. T., Gerbes, A. L., DÜrr, E. M., Schauer, R., Kessler, M., JelineK, T., LÖSCHER, T., Bilzer, M. (2003): 52-year-old patient with subcutaneous spaceocupying lesion in imunosupression. Internist., 44(6): 740 - 745. DOI: 10.1007/s00108-003-0862-3

Liance, M., Bresson-Hadni, S., Vuitton, D. A., Lenys, D., Carbillet, J. P., Houin, R. (1992): Effects of cyclosporin $\mathrm{A}$ on the course of murine alveolar echinococcosis and on specific cellular and humoral immune responses against Echinococcus multilocularis. Int. J. Parasitol., 22(1): 23 - 28. DOI: 10.1016/00207519(92)90075-V

Liance, M., Ricard-Blum, S., Emery, I., Houin, R., VuitTon, D. A. (1998): Echinococcus multilocularis infection in mice: in vivo treatment with a low dose of IFN-gamma decreases metacestode growth and liver fibrogenesis. Parasite. 5(3): 231- 237

MiterpÁKovÁ, M., DubinskÝ, P., REITERovÁ, K., StAnKo, M. (2006): Climate and enviromental factors influencing Echinococcus multilocularis ocurrence in the Slovak Republic. Ann. Agric. Environ. Med., 13(2): 235 - 242 
MiterpákovÁ, M., HurníkovÁ, Z., Antolová, D., DUBINSKÝ, P. (2009): Endoparasites of red fox (Vulpes vulpes) in the Slovak Republic with the emphasis on zoonotic species Echinococcus multilocularis and Trichinella spp. Helminthologia, 46(2): 73 - 79. DOI: 10.2478/s11687-009-0015-x

MORAR, R., FELDMAN, C. (2003): Pulmonary echinococcosis. Eur. Respir. J,. 21(6): 1069 - 1077. DOI: 10.1183/09031936.03.00108403

Palmiero, G., Ciampi, R., Gallo, R., Federico, S., SABBATINI, M. (2008): Liver echinococcosis in a renal transplant patient: a particularly intriguing case report. $J$. Nephrol. 21(3): $442-445$

PorubcovÁ, J., DVOROŽŇÁKOVÁ, E., ŠEvČíKOVÁ, Z. (2007a): Immunomodulative effect of glucan and/or glucan supplemented with zinc in albendazole therapy for murine alveolar echinococcosis. Parasitol. Res., 101: $751-760$. DOI: $10.1007 / \mathrm{s} 00436-007-0545-4$

Porubcová, J., DvorožŇÁkovÁ, E., ŠEvČíkovÁ, Z. (2007b): Immune response of mice to Echinococcus multilocularis infection after therapy with amphotericin B colloidal dispersion. Helminthologia, 44(2): 47-56, DOI: 10.2478/s11687-007-0003-y

Romig, T., Zeyhle, E., Macpherson, C. N. L., ReEs, P. H., Were, J. O. B. (1986): Cyst growth and spontaneous cure in hydatid disease. Lancet, 1(8485): 861 - 862. DOI: 10.1016/S0140-6736(86)90974-8

SAiler, M., Solder, B., Allerberger, F., ZAKNun, D., Feichtinger, H., Gottstein, B. (1997): Alveolar echinococcosis of the liver in a six-year-old girl with acquired immunodeficiency syndrome. J. Pediatr., 130(2): 320 - 323. DOI: 10.1016/S0022-3476(97)70364-0

SCHWEIGER, A. (2007): Human alveolar echinococcosis after fox population inrease, Switzerland. Emerg. Infect.
Dis., 13(6): 878 - 882. DOI: 10.3201/eid1306.061074

Sobrino, J. M., Pulpón, L. A., Crespo, M. G., Silva, L., Segovia, J., Serrano-Fiz, S., Burgos, R., Montero, C. G., PerafÁN, A., TÉllez, G. (1993): Heart transplantation in a patient with liver hydatidosis. J. Heart Lung Transplant., 12(3): $531-533$

Sqalli, T. H., Buchler, M., NajJar, A., Paris, A., Halimi, J. M., Nivet, H., Anthonioz, P., Philippe Bourlier, P., DuOnG, T. H., LeBranchu, Y. (2009): Hydatid cyst disaease in a renal allograft recipient. Saudi J. Kidney Dis. Transpl. 20(6): 1057 - 1060

Vuitton, D. A., GotTstein, B. (2010): Echinococcus multilocularis and its intermediate host: a model of parasite-host interplay. J. Biomed. Biotechnol., 2010, ID 923193. DOI: 10.1155/2010/923193

Vuitton, D. A., Zhang, S. L., YANG, Y., Godot, V., Beurton, I., Mantion, G., Bresson-Hadni, S. (2006): Survival strategy of Echinococcus multilocularis in the human host. Parasitol. Int., 55: 51 - 55. DOI: 10.1016/ j.parint.2005.11.007

WÉclawiack, H., Kamar, N., Mehrenberger, M., Frugier, C. G., Modesto, A., Izopet, J., Ribes, D., SAllusto, F., Rostaing, L. (2008): Alpha-interferon therapy for chronic hepatitis $\mathrm{C}$ may induce acute allograft rejection in kidney transplant patients with failed allografts. Nephrol. Dial. Transplant., 23(3): 1043 - 1047. DOI: $10.1093 / \mathrm{ndt} / \mathrm{gfm} 678$

ZingG, W., Renner-Schneiter, E. C., Pauli-Magnus, C., Renner, E. L., Vanoverbeck, J., Schlapfer, E., Weber, M., Weber, R., Opravil, M., Gottstein, B., Speck, R. F. (2004): Swiss HIV Cohort Study. Alveolar echinococcosis of the liver in an adult with human immunodeficiency virus type-1 infection. Infection 32(5): 299 - 302. DOI: 10.1007/s15010-004-3134-9 